\title{
Structural characterization and complex impedance studies on fast ion conducting mixed system $\left(\mathrm{SbI}_{3}\right)_{x}-\left(\mathrm{Ag}_{2} \mathrm{CrO}_{4}\right)_{1-x}$
}

\author{
S AUSTIN SUTHANTHIRARAJ ${ }^{*}$ and S SAROJINI ${ }^{\dagger}$ \\ Department of Energy, University of Madras, Guindy Campus, Chennai 600 025, India \\ †P and Research Department of Physics, Queen Mary’s College, Chennai 600 004, India
}

MS received 15 July 2012; revised 18 February 2013

\begin{abstract}
This paper deals with preparation and physico-chemical characterization of a new mixed system, $\left(\mathrm{SbI}_{3}\right)_{x}-\left(\mathrm{Ag}_{2} \mathrm{CrO}_{4}\right)_{1-x}(0 \cdot 1 \leq x \leq 0 \cdot 9)$, undertaken with a view to evaluate silver ion transport properties and identify those fast ion conducting compositions. Polycrystalline samples of various compositions were synthesized by rapid melt-quenching method. Powder X-ray diffraction (XRD) analysis in conjunction with differential scanning calorimetry (DSC) and electrical transport evaluation involving silver ionic transport number and temperaturedependent electrical complex impedance measurements were carried out in order to identify the different phases responsible for the conduction mechanism. Realization of a fast ionic conductivity value of $3.2 \times 10^{-2} \mathrm{~S} \mathrm{~cm}^{-1}$ in the case of the composition, $\left(\mathrm{SbI}_{3}\right)_{0.3}-\left(\mathrm{Ag}_{2} \mathrm{CrO}_{4}\right)_{0.7}$, at room temperature due to silver ion transport has been discussed in terms of observed structural and thermal characteristics. A detailed analysis of conductivity spectra pertaining to the best conducting system, $\left(\mathrm{SbI}_{3}\right)_{0 \cdot 3}-\left(\mathrm{Ag}_{2} \mathrm{CrO}_{4}\right)_{0.7}$, has also been presented.
\end{abstract}

Keywords. Electrical conductivity; impedance; DSC; XRD; conductivity spectra.

\section{Introduction}

In the realm of modern materials research involving new materials, solid state devices appear to be significant to our economies and fascinating too. For instance, remarkable interest witnessed over the past few decades in solid electrolytes or fast ionic systems stems from their device applications in solid state batteries, fuel cells, sensors and so on. Fast ion conducting glasses exhibit certain advantages over their crystalline counterparts owing to their isotropic properties, ease of formation and tailor-made properties with a desired change in composition. Silver iodide which is one of the well known fast ionic conducting solid exists in three polymorphic forms as $\alpha$ (bcc), $\beta$ (wurtzite) and $\gamma$ (zincblende) wherein $\alpha$ is stable above $420 \mathrm{~K}$, is the fast ionic phase, which has been extensively studied (Patnaik and Sunandana 1998). However, $\alpha$-AgI is thermodynamically stable only in the temperature range between 420 and $828 \mathrm{~K}$ and $\beta$ and $\gamma$ $\mathrm{AgI}$ are the stable phases at temperatures lower than $420 \mathrm{~K}$. The conductivities of $\beta$ or $\gamma$-AgI are as low as about $10^{-5}$ $\mathrm{S} \mathrm{cm}{ }^{-1}$ at room temperature. Various techniques have been employed to achieve fast ionic conduction at room temperature in AgI-based systems either by adding second components to $\mathrm{AgI}$ to form new compounds such as $\mathrm{Ag}_{3} \mathrm{SI}$ and $\mathrm{RbAg}_{4} \mathrm{I}_{5}$ or by adding various kinds of silver oxysalts to form superionic conducting solids (Saito et al 1993). Literature references in the field of fast ion conducting systems

\footnotetext{
*Author for correspondence (suthan98@gmail.com)
}

over the past three decades portrays AgI-based fast ionic systems as promising candidates possessing ionic conductivities in the order of $10^{-3}-10^{-1} \mathrm{~S} \mathrm{~cm}^{-1}$ at room temperature (Chandra 1981; Minami 1983; Kanchan et al 2004; Bhattacharya and Ghosh 2005; Nowinski et al 2007; Veeranna Gowda and Anavekar 2007). A highly disordered structure is an essential feature for the superionic conductors in view of their applications to solid-state ionic devices and also thorough comparative investigation of thermal and other properties of these amorphous superionic conductors is highly desirable particularly the glass transition and crystallization kinetic studies. In the isothermal crystallization kinetics, the temperature is kept constant whereas in non isothermal measurements the DSC experiments are performed at different heating rates. Both the techniques lead to determination of thermodynamic parameters such as glass $\left(T_{\mathrm{g}}\right)$ and amorphous $\leftrightarrow$ crystalline transition $\left(T_{\mathrm{c}}\right)$ temperatures and the corresponding enthalpy and entropy changes ( $\Delta H$ and $\Delta S$, respectively), activation energies for structural relaxation $\left(E_{\mathrm{s}}\right)$ and crystallization $\left(E_{\mathrm{c}}\right)$, and the order parameter ( $n$ ) (Dalvi et al 2005).

In order to arrive at new series of fast ionic systems in a cost-effective manner, researchers in the recent past replaced AgI with other metal halides such as $\mathrm{CdI}_{2}, \mathrm{CuI}$, $\mathrm{ZnI}_{2}, \mathrm{PbI}_{2}$ and alkali halides like $\mathrm{NaI}$ or $\mathrm{KI}$ (Viswanathan and Suthanthiraraj 1992, 1993; Suthanthiraraj et al 2001; Padmasree et al 2005; Suthanthiraraj and Vinod Mathew 2005 ) resulting in electrical conductivities comparable to that of their AgI-based counterparts. On the other hand, the presence of certain cations such as $\mathrm{Cs}^{+}, \mathrm{Cu}^{+}, \mathrm{Zn}^{2+}, \mathrm{Pb}^{2+}$ or 
$\mathrm{Sb}^{3+}$ ion led to possible coordination with the oxygen ion within the oxyanion framework thereby facilitating easy conduction pathways for $\mathrm{Ag}^{+}$ions to move towards an iodinerich environment (El Damrawi et al 2000; Renard et al 2002) and the role of silver oxysalt $\mathrm{Ag}_{2} \mathrm{CrO}_{4}$ in forming glassy networks has already been well established in the literature (Viswanathan and Suthanthiraraj 1992; Durga Rani and Hariharan 1996). The present work has been undertaken with an aim of arriving at a family of silver ion conducting fast ionic solids by appropriately substituting antimony iodide, $\mathrm{SbI}_{3}$ for $\mathrm{AgI}$ into the network of a typical silver oxysalt, viz. silver chromate $\mathrm{Ag}_{2} \mathrm{CrO}_{4}$ in order to form a new mixed system, $\mathrm{SbI}_{3}-\mathrm{Ag}_{2} \mathrm{CrO}_{4}$ and understanding their structural, thermal and electrical characteristics.

\section{Experimental}

\subsection{Sample preparation}

Some of the widely used preparation techniques include melt quenching, flash evaporation, sol-gel process etc. In the preparation of solids, usually special care has to be taken to use proper stoichiometric quantities, pure starting materials and to ensure that the reaction is completed because it is usually not possible to purify a solid once it has been formed. The method chosen for any solid will depend not only on the composition of the solid but also on the form it is required for its proposed use. In the melt-quenching method, the raw materials are melted above the melting point and then rapidly quenched with liquid nitrogen. To achieve a homogeneous mix of small particles, it is necessary to be very thorough in grinding the reactants. Hence, all the starting materials are ground well to attain a small particle size, and hence are very well mixed to maximize the surface contact area and minimize the distance that the reactants have to diffuse. Evacuated tubes are employed when products or reactants are sensitive to air or water or are volatile. Depending on the temperature of reaction, Pyrex or silica (quartz) are the common choices for such reaction tubes, as they are fairly inert, and may be sealed using vacuum system for easy handling. One of the benefits of the melt-quench technique is that the resultant solid material from a high quenching rate is chemically homogenous and therefore, it is possible to obtain different shapes and forms which may be the desired characteristic in device applications.

In the present investigation, the conventional meltquenching technique involving vacuum-sealed quartz tubes has been employed in order to prevent the starting materials from reacting with atmospheric oxygen and hence forming any impurity compounds. Moreover, this technique averts the possibility of the resultant melt seeping into the semi-porous boat at high temperatures as generally found in the case of open-air ceramic boat-quenching technique, thus leading to a reduction in the yield of the final product. Accordingly, analar grade chemicals of antimony iodide, $\mathrm{SbI}_{3}$ and silver chromate, $\mathrm{Ag}_{2} \mathrm{CrO}_{4}$, were used as raw materials for the synthesis of different compositions of the chosen binary system, $\left(\mathrm{SbI}_{3}\right)_{x}-\left(\mathrm{Ag}_{2} \mathrm{CrO}_{4}\right)_{1-x}$, where $x=0 \cdot 9,0 \cdot 8,0 \cdot 7,0 \cdot 6$, $0.5,0.4,0.3,0.2$ and 0.1 mole fraction, respectively by annealing mixtures of appropriate amounts of the starting materials in a vacuum-sealed quartz ampoule kept over a ceramic boat at $873 \mathrm{~K}$ for $6 \mathrm{~h}$ in a high temperature furnace and rapidly quenching the molten mixture in a liquid nitrogen bath. The resultant products were finely powdered using a pestle and mortar and stored in a darkened desiccator for further investigation.

\subsection{Powder X-ray diffraction}

$\mathrm{X}$-ray diffraction (XRD) measurements were carried out on all the powdered samples of the mixed system, $\left(\mathrm{SbI}_{3}\right)_{x}-$ $\left(\mathrm{Ag}_{2} \mathrm{CrO}_{4}\right)_{1-x}$, where $x=0 \cdot 9,0 \cdot 8,0 \cdot 7,0 \cdot 6,0 \cdot 5,0 \cdot 4,0 \cdot 3$, 0.2 and 0.1 mole fraction, respectively at room temperature using a Siefert X-ray Diffractometer with $\mathrm{CuK} \alpha_{1}$ radiation $(\lambda=1.541 \AA)$.

\subsection{Differential scanning calorimetry}

The thermal events were recorded for all the specimens of the system, $\left(\mathrm{SbI}_{3}\right)_{x}-\left(\mathrm{Ag}_{2} \mathrm{CrO}_{4}\right)_{1-x},(0 \cdot 1 \leq x \leq 0 \cdot 9)$, in the temperature range of 323-573 K using a Perkin Elmer model DSC-7 differential scanning calorimeter at a heating rate of $20 \mathrm{~K} \mathrm{~min}^{-1}$ with platinum as the reference material and aluminum sample containers.

\subsection{Complex impedance analysis}

The freshly-prepared solid samples of the mixed system, $\left(\mathrm{SbI}_{3}\right)_{x}-\left(\mathrm{Ag}_{2} \mathrm{CrO}_{4}\right)_{1-x}(0 \cdot 1 \leq x \leq 0 \cdot 9)$, were ground and pressed together with appropriate silver electrodes on both sides under a pelletizing pressure of 5 ton $\mathrm{cm}^{-2}$ in order to make circular pellets of $8 \mathrm{~mm}$ diameter. These electrodes comprised of metallic silver powder and sample mixed in the weight ratio of $2: 1$. Any metallic electrode which is different from the components of the mixed conductors may be used as an ion blocking electrode or as a non-blocking electrode. For example, Pt electrodes were used as ion blocking electrodes for electronic conductivity measurements in oxide ion electrolytes in d.c. method (Ahn et al 2011). Similarly, Au electrodes were used as non-blocking electrodes in order to enhance electronic conductivity.

In the case of yttria-stabilized zirconia (YSZ), choice of electrode metal has a significant influence on the electrode properties with $\mathrm{Ag}$ as the best and $\mathrm{Au}$ as the poorest. Hence, the respective electrode resistance values could be ranked by $R_{\mathrm{Ag}}<R_{\mathrm{Au}}<R_{\mathrm{Pt}}$, with $R_{\mathrm{Au}} \sim 10^{2}-10^{3} \times R_{\mathrm{Pt}}$. On the other hand, for the stabilized $\delta$-bismuth sesqui-oxides, in particular, $\left(\mathrm{Bi}_{2} \mathrm{O}_{3}\right)_{0.75}\left(\mathrm{Er}_{2} \mathrm{O}_{3}\right)_{0.25}$ (abbreviated as $\mathrm{BiEr} 25$ ), there is very little difference in performance between $\mathrm{Pt}$ and $\mathrm{Au}$ electrodes with similar electrode morphology. In the case of $\mathrm{Bi}_{2} \mathrm{Cu}_{0.1} \mathrm{~V}_{0.9} \mathrm{O}_{5.35}$ system, similar trend was observed 
in the performance of $\mathrm{Au}, \mathrm{Pt}$ and $\mathrm{Ag}$ electrode metals (Boukamp 2000).

The complex impedance measurements were carried out using a computer-controlled Hewlett-Packard model HP4284A Precision LCR Meter in the frequency range of $20 \mathrm{~Hz}-1 \mathrm{MHz}$ over the temperature region 298-435 K. Essentially, the frequency response of the sample under analysis could be represented by an equivalent circuit consisting of a parallel combination of circuit elements, $R_{\mathrm{b}}$ and $C_{\mathrm{g}}$, denoting the bulk resistance and geometric capacitance, respectively, whereas the resultant intercept of the semicircular arcs of impedance plot (i.e. plot of $Z^{\prime \prime}$ vs $Z^{\prime}$ where $Z^{\prime}$ and $Z^{\prime \prime}$ denote the real and imaginary parts of the complex impedance $Z^{*}$ ) on the real axis would indicate the bulk resistance, $R_{\mathrm{b}}$, of the specimen. A schematic representation of a fast ionic solid sandwiched between two nonblocking (i.e. reversible silver) electrodes together with the relevant equivalent circuit and impedance plot is shown in figure 1 (Macdonald 1973, 1974, 1987; Suthanthiraraj and Mala 2003).

All the observed impedance plots were best fitted internally by means of the Boukamp equivalent circuit software package incorporated within the computer. Equivalent circuits are traditionally used to model a.c. impedance data. An equivalent electrical circuit (EEC) is an electrical circuit with the same impedance spectrum as the experimental data. The values and arrangement of the circuit elements ideally represent physical properties or phenomena. Electrochemical impedance spectroscopy (EIS) is a powerful diagnostic technique that finds extensive use in electrochemistry, especially for the multi-electron transfer processes. Combinations of purely resistive, capacitive, or inductive behaviours do not necessarily describe the response of all systems and hence constant phase elements (CPE) are used to model this behaviour (Biendicho and West 2012).

The experimental impedance data were well fitted using the fitting procedure according to Boukamp, by treating various impedance parameters as variables of applied voltage. For each set of experimental data, the parameters of EEC were fitted using the complex nonlinear least square (CNLS) fitting procedure using the Boukamp's equivalent circuit software. The complex nonlinear least squares (CNLS) method is one of the most common approaches for modelling impedance data. CNLS is used to fit real and imaginary parts or the magnitude and phase of experimental impedance or admittance data to an equivalent circuit or a rational function. It is a convenient method for fitting data to functions (Boukamp 1986).

The impedance analyses of the samples were performed by nonlinear least square (NLLS) fitting procedure. NLLS fitting is performed in two steps, in the partial NLLS fit, suitable points are selected in a straight line and part of the impedance data through which a tangential line is drawn. The intersection of the line with the real axis gives the bulk resistance. By choosing a set of three data points in the high frequency depressed semicircle, NLLS fit yields the values for the impedance and CPE parameters. Later, both inclined straight line and semicircle parts are simultaneously fitted to the NLLS fit procedure to yield a set of parameters (e.g. circuit elements) of the equivalent circuit. Thus, performed analysis reduces most of the systematic errors and deduces the parameters for an equivalent circuit. The complex nonlinear least square method centres on minimizing the object function $S$ with respect to the parameters $a_{\mathrm{k}}$ of the model function, $Z\left(\omega, a_{\mathrm{k}}\right)$ :

$$
\sum_{i=1}^{N} w_{\mathrm{i}}\left\{\left[Z_{\mathrm{re}, \mathrm{i}}-Z_{\mathrm{re}}\left(\omega_{\mathrm{i}}, a_{\mathrm{k}}\right)\right]^{2}+\left[Z_{\mathrm{im}, \mathrm{i}}-Z_{\mathrm{im}}\left(\omega_{\mathrm{i}}, a_{\mathrm{k}}\right)\right]^{2}\right\},
$$

where $Z_{\mathrm{re}, i}+j Z_{\mathrm{im}, i}$ represents the measured impedance at frequency, $\omega_{i}$ and $w_{i}$ the weighed factor. An important control tool is the distribution of the residuals $v s$ frequency. For a good match between data and model, the residuals should be randomly distributed around the $\log \omega$ axis (Boukamp 2004).

The experimental impedance data were well fitted using the fitting procedure according to Boukamp by treating the various impedance parameters as variables of applied voltage. For each set of experimental data, parameters of EEC were fitted using the complex nonlinear least square (CNLS) fitting procedure. The goodness of fit value of $\chi$ - quadrate of $10^{-4}$ or less indicates a reasonably good fit using a minimum number of elements within an error of 5\% (Hull et al 2002; Metikos et al 2003).

Thus, the values of $R_{\mathrm{b}}$ for individual samples at various temperatures could be estimated accurately during the present investigation.

\subsection{Silver ionic transport number measurements}

The electromotive force (EMF) method was employed for the estimation of silver ionic transport number $\left(t_{\mathrm{Ag}+}\right)$ in each composition of the present system at room temperature. Accordingly, a galvanic cell was fabricated with a configuration

$$
(-) \mathrm{Ag}+\text { sample } / \text { sample } / \mathrm{I}_{2}(+)
$$

where a powder mixture of metallic silver powder and the sample taken in the weight ratio 2:1 was used as anode. The cell components were cascaded and pressed together into a circular pellet at a pelletizing pressure of 5 ton $\mathrm{cm}^{-2}$ so as to constitute the galvanic cell. The values of open circuit voltage $\left(E_{\mathrm{t}}\right),(\mathrm{OCV})$ of such solid-state electrochemical cells were measured and compared with the thermodynamic value of $687 \mathrm{mV}\left(E_{\mathrm{o}}\right)$ reported for the $\mathrm{Ag} / \mathrm{I}_{2}$ couple for arriving at room temperature silver ionic transport number $\left(t_{\mathrm{Ag}+}\right)$ data corresponding to each composition of the present mixed system (Suthanthiraraj and Mala 2003) where

$$
t_{\mathrm{Ag}+}=\frac{E_{\mathrm{t}}}{E_{\mathrm{o}}}
$$

and for fast ionic solids with high ionic conductivities, the value of $t_{\mathrm{Ag}+}$ is found to be almost unity. 


\section{Results and discussion}

\subsection{Phase identification from XRD data}

The observed room temperature powder X-ray diffraction (XRD) patterns for the set of nine different compositions of the mixed system $\left(\mathrm{SbI}_{3}\right)_{x}-\left(\mathrm{Ag}_{2} \mathrm{CrO}_{4}\right)_{1-x}$ corresponding to $x=0.9,0.8,0.7,0.6,0.5,0.4,0.3,0.2$ and 0.1 mole fraction are presented in figure $2(\mathrm{a}-\mathrm{i})$. A careful scrutiny of all XRD peaks was performed by means of XRD analysis software in conjunction with JCDPS diffraction data in order to identify the various phases formed. It is apparent from figure 2 that most of the observed XRD patterns exhibit welldefined peaks indicating the presence of polycrystalline solid materials except the XRD pattern designated as ' $\mathrm{g}$ ' corresponding to specimen having $x=0.3$ mole fraction, respectively. This implies that all those $\mathrm{SbI}_{3}$-rich compositions are essentially polycrystalline in nature. The fact that the particular composition containing $x=0.3$ mole fraction has been characterized by broad and very much less intense peaks in XRD pattern tends to suggest the formation of relatively disordered-type of material within this specimen. Interestingly, the occurrence of an intense peak at $2 \theta=26.67^{\circ}$ along with a series of less-intense peaks at $2 \theta=35.1$ and $41.8^{\circ}$ in the case of XRD pattern denoted as 'a' may be attributed to the existence of excess or unreacted starting material viz. $\mathrm{SbI}_{3}$, owing to the presence of characteristic [ $\left.h k l\right]$ lines

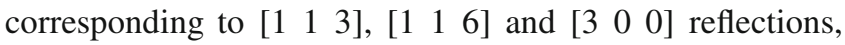
respectively (JCDPS File no. 740456) considering the richness of $\mathrm{SbI}_{3}$ in this composition (having 0.9 mole fraction) as compared to $\mathrm{Ag}_{2} \mathrm{CrO}_{4}$. On the other hand, those patterns represented as ' $b$ ' and ' $c$ ' in figure 1 show a gradual shift associated with the above reflections, thus suggesting the onset of formation of certain new phases in the case of specimens containing $x=0.8$ and 0.7 mole fraction as a result of probable solid-state reactions occurring between $\mathrm{SbI}_{3}$ and $\mathrm{Ag}_{2} \mathrm{CrO}_{4}$. Furthermore, in the present XRD pattern designated as 'd', a set of characteristic peaks corresponding to the presence of AgI cubic phase (space group $F 43 m$ ) (JCDPS file no. 780641) are noticed in the form of

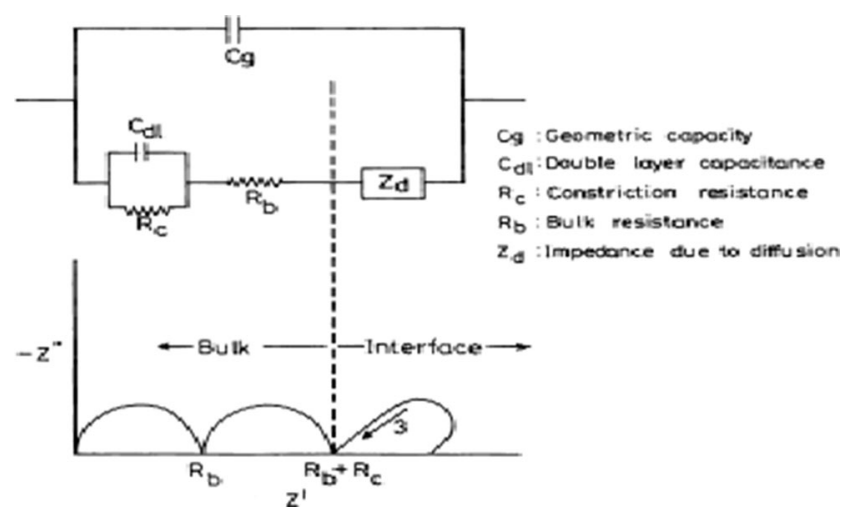

Figure 1. Schematic representation of equivalent circuit and impedance plot.

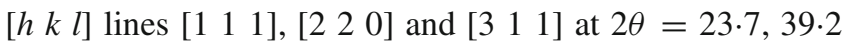
and $46.3^{\circ}$, respectively thus revealing the formation of $\mathrm{AgI}$ as one of the reaction products in this particular composition containing 0.6 mole fraction of $\mathrm{SbI}_{3}$. Similarly, figure 1 tends to confirm the existence of AgI phase in the case of two consecutive compositions possessing 0.5 and 0.4 mole fractions of $\mathrm{SbI}_{3}$ (i.e. $x=0.5$ and 0.4 ) owing to the occurrence of intense peaks around $2 \theta=23.7,39 \cdot 2$ and $46 \cdot 3^{\circ}$ corresponding to pure AgI in the XRD pattern denoted as ' $\mathrm{e}$ ' and ' $\mathrm{f}$ '. Furthermore, XRD pattern designated as ' $\mathrm{f}$ ' appears to be less intense compared to the pattern marked as ' $\mathrm{e}$ '.

A careful examination of figure 2 suggests that in the case of compositions corresponding to $x=0.1$ and 0.2 mole fractions, the observed XRD peaks are relatively less intense compared to that of remaining compositions. Typically, the composition having $x=0.1$ mole fraction is found to exhibit a set of three characteristic XRD peaks of AgI at $2 \theta=23.7$,

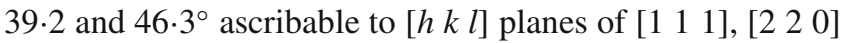

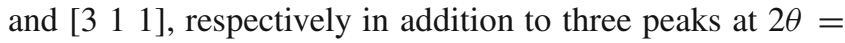
$31.1,31.4$ and $32.3^{\circ}$ owing to the presence of $\mathrm{Ag}_{2} \mathrm{CrO}_{4}$ in orthorhombic phase (space group, Pnma) which may be

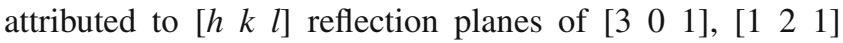
and [ $\left.\begin{array}{lll}0 & 0 & 2\end{array}\right]$, respectively (JCDPS file no. 780641; JCDPS file no. 720858). In the case of $x=0.2$ mole fraction, it is seen from figure 2 that three characteristic XRD peaks of AgI appear at $2 \theta=23.7,39.2$ and $46.3^{\circ}$ ascribable to

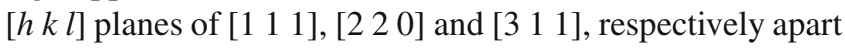
from those three characteristic peaks of $\mathrm{CrSbO}_{4}$ in tetragonal phase (space group, $P 4_{2} / \mathrm{mnm}$ ) observed at $2 \theta=27 \cdot 5,35 \cdot 2$ and $53.7^{\circ}$ corresponding to $\left[\begin{array}{lll}h k & l\end{array}\right]$ planes of [ $\left[\begin{array}{lll}1 & 1 & 0\end{array}\right],\left[\begin{array}{lll}1 & 0 & 1\end{array}\right]$ and [2 11 1], respectively (JCDPS file no. 780641; JCPDS file no. 351288). On the other hand, it is interesting to note from figure 1 that less intense peaks corresponding to AgI appear at $2 \theta=23.7,39.2$ and $46.3^{\circ}$ owing to the reflection planes

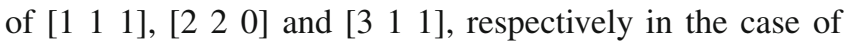
composition having $x=0.3$ mole fraction (JCDPS file no. 780641). The above compositions are thus found to be polycrystalline in nature. The disordered nature of the composition corresponding to $x=0.3$ mole fraction as revealed by the present XRD results appears to suggest that such specimen would be expected to exhibit interesting ion-transport features too, as discussed in the subsequent section.

It is inferred that AgI phase is formed only in certain compositions as one of the constituents wherein favourable experimental conditions exist for possible ion exchange chemical reactions to occur within the molten specimens of the chosen multi-phase system, $\mathrm{SbI}_{3}-\mathrm{Ag}_{2} \mathrm{CrO}_{4}$ and hopping of $\mathrm{Ag}^{+}$ions within the lattice may lead to a highly disordered state which in turn would influence the behaviour of electrical characteristics of those compositions as well.

\subsection{Differential scanning calorimetric analysis}

The differential scanning calorimetric (DSC) traces obtained for the nine different compositions of the mixed system $\left(\mathrm{SbI}_{3}\right)_{x}-\left(\mathrm{Ag}_{2} \mathrm{CrO}_{4}\right)_{1-x}$, where $x=0.9,0.8,0.7,0.6,0.5$, 


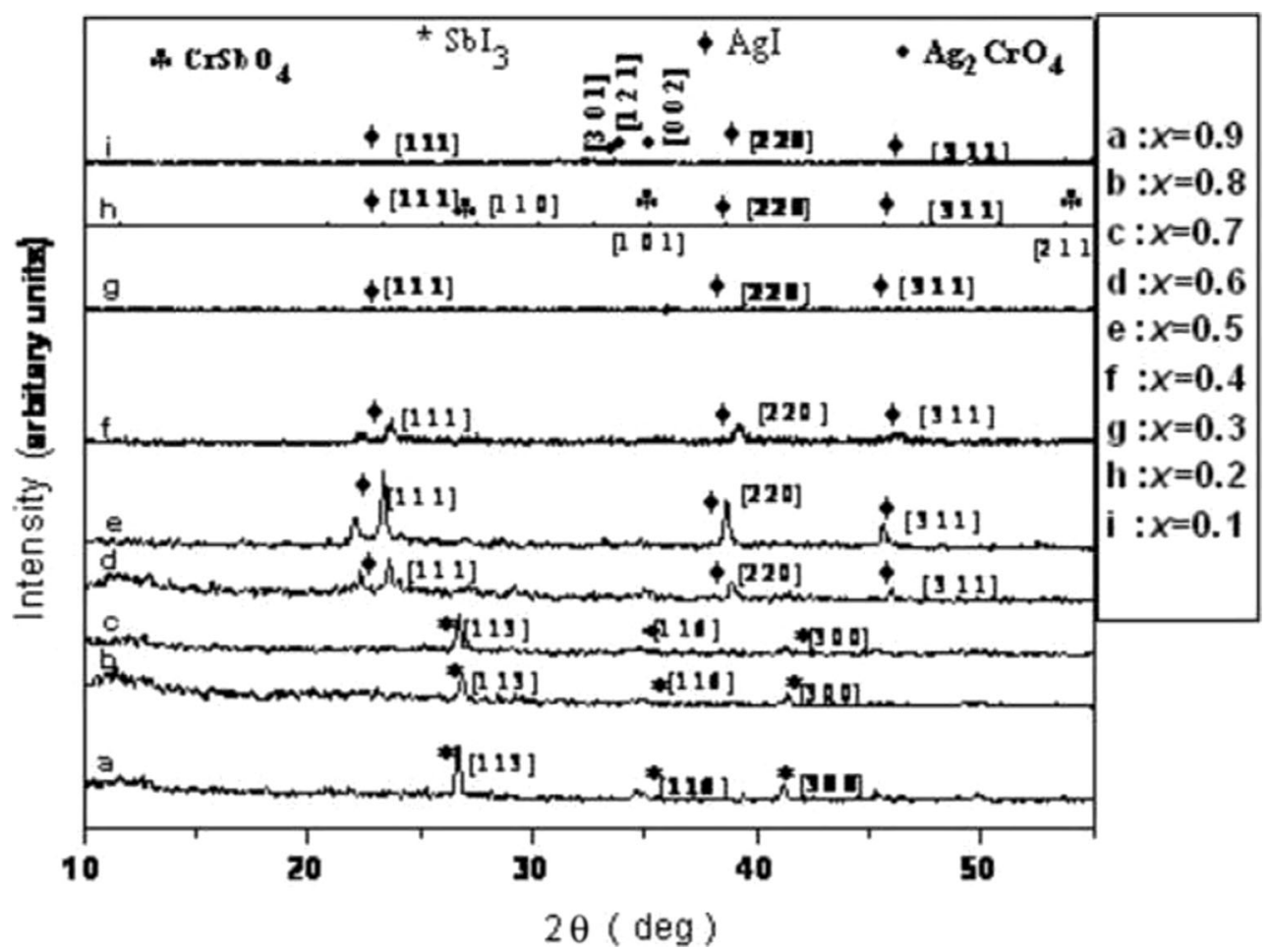

Figure 2. Powder XRD patterns obtained for different compositions of mixed system $\left(\mathrm{SbI}_{3}\right)_{1-x}-$ $\left(\mathrm{Ag}_{2} \mathrm{CrO}_{4}\right)_{1-x}(0 \cdot 1 \leq x \leq 0 \cdot 9)$.

$0 \cdot 4,0 \cdot 3,0.2$ and $0 \cdot 1$ mole fractions as a, b, c, d, e, f, g, h and $i$, respectively are shown in figure 3 . Figure 3 suggests that DSC traces recorded over the temperature range 323-460 K exhibit certain interesting features depending on the amounts of reaction products formed in the composition range of $x=0.9-0.1$ mole fraction. For instance, DSC curve obtained for the particular composition containing $x=0.9$ mole fraction exhibits an endothermic peak at $446 \mathrm{~K}$ which corresponds to the melting temperature of $\mathrm{SbI}_{3}$. In the case of those five different compositions having $x=0 \cdot 8$, $0.7,0.6,0.5$ and 0.4 mole fractions, the set of endothermic peaks noticed at $431,429,428,428$ and $428 \mathrm{~K}$, respectively confirm the presence of $\mathrm{AgI}$ as a new phase formed as a reaction product between $\mathrm{SbI}_{3}$ and $\mathrm{Ag}_{2} \mathrm{CrO}_{4}$. Furthermore, it is also evident that those endothermic peaks appearing at 421,420 and $418 \mathrm{~K}$ in the case of compositions containing $x=0 \cdot 3,0.2$ and 0.1 mole fractions respectively correspond to the $\beta \rightarrow \alpha$ phase transition of pure AgI occurring at $420 \mathrm{~K}$ (Suthanthiraraj et al 2001; Suthanthiraraj and Mala 2003; Rivolta et al 1988). Thus, the present DSC results are found to be in good agreement with XRD data.

It is interesting to notice from the present DSC data that for compositions corresponding to lower contents of $\mathrm{SbI}_{3}$ such as $x=0.1,0.2$ and 0.3 mole fractions, there is an endothermic DSC peak appearing at or near $420 \mathrm{~K}$ as revealed by figure 3 , due to the $\beta \rightarrow \alpha$ phase transition of AgI. These observations may be attributed to the fact that the addition of $\mathrm{SbI}_{3}$ into the effective $\mathrm{Ag}_{2} \mathrm{O}-\mathrm{CrO}_{3}$ network i.e.
$\mathrm{Ag}_{2} \mathrm{CrO}_{4}$, would yield a higher concentration of $\mathrm{I}^{-}$ions compared to the conventional $\mathrm{AgI}-\mathrm{Ag}_{2} \mathrm{O}-\mathrm{CrO}_{3}$ framework due to the presence of three $\mathrm{I}^{-}$ions associated with each $\mathrm{Sb}^{3+}$ entity in $\mathrm{SbI}_{3}$ as against the release of only one $\mathrm{I}^{-}$ion from each mole of AgI (El Damrawi et al 2000). In other words, the present DSC results tend to reveal favourable impact of $\mathrm{SbI}_{3}$ as an $\mathrm{I}^{-}$ion source for the formation of crystalline $\mathrm{AgI}$ in a variety of compositions of the chosen system.

\subsection{Electrical conductivity and ionic transport number results}

Figure 4 depicts complex impedance plots obtained at different temperatures $(298-420 \mathrm{~K})$ for a composition corresponding to $x=0.3$ mole fraction in the mixed system, $\left(\mathrm{SbI}_{3}\right)_{x}-\left(\mathrm{Ag}_{2} \mathrm{CrO}_{4}\right)_{1-x}$. It is interesting to note from figure 4 that each Nyquist plot consists of a depressed semicircular arc, thus revealing the presence of a bulk resistance $\left(R_{\mathrm{b}}\right)$ in parallel connection with a geometric capacitance $\left(C_{\mathrm{g}}\right)$ as reported earlier in the case of other solid electrolyte materials (Viswanathan and Suthanthiraraj 1992). According to Armstrong et al (1974), ionic single crystals with high conductivity values exhibit semicircular complex impedance plots with simple behaviour intersecting the real axis at two places at or near origin $(\omega=\infty)$ and at $R_{\mathrm{b}}(\omega=0)$ and the difference between these two values corresponds to the bulk resistance of the sample. Similarly, pure AgI (Armstrong et al 1972), which exhibits a high ionic conductivity, also 


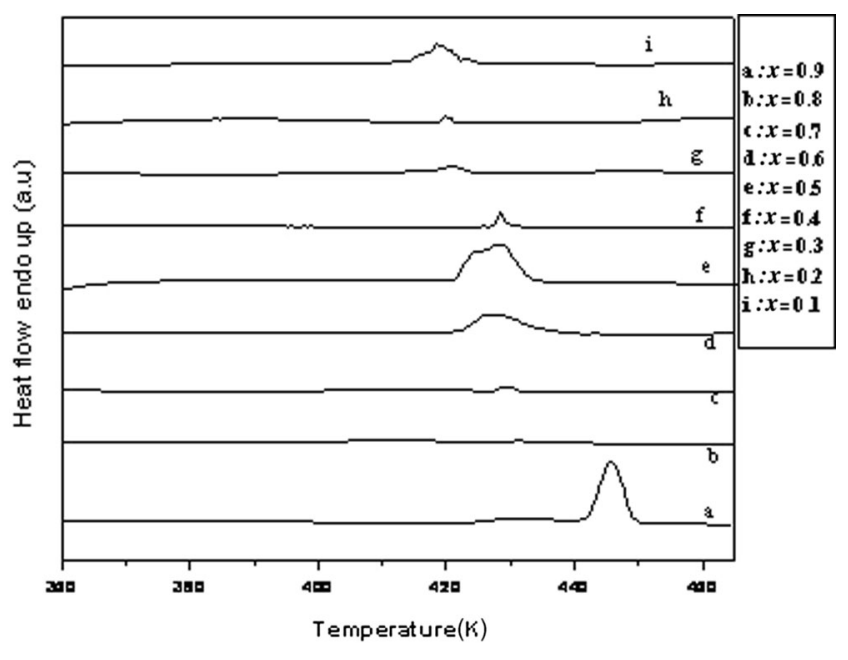

Figure 3. DSC traces for different compositions of mixed system, $\left(\mathrm{SbI}_{3}\right)_{0 \cdot 3}-\left(\mathrm{Ag}_{2} \mathrm{CrO}_{4}\right)_{0 \cdot 7}(0 \cdot 1 \leq x \leq 0 \cdot 9)$.

shows a proper semicircular plot. Generally, fast ionic conductors are polycrystalline in nature with inter-granular grain boundary effects (Hodge et al 1976) and could not be represented as single parallel RC equivalent circuit which exhibits complete semicircular arc. Instead, they are represented as series combination of number of parallel RC elements representing distribution of conducting elements of various grains present in the system (Macdonald 1992). Hence, the complex impedance plot of the present solid electrolyte system appears to have two incomplete semicircular arcs including a high frequency one corresponding to bulk resistance $\left(R_{\mathrm{b}}\right)$ of the sample in parallel with geometric capacitance, $C_{\mathrm{g}}$ and a low frequency arc representing double layer capacitance, $C_{\mathrm{dl}}$, of the electrode-electrolyte interface (Archer and Armstrong 1980). Actually, the high frequency region shows a portion of a semicircular arc whose centre is depressed below the $x$ axis with an angle of inclination as $\alpha \pi / 2$, where ' $\alpha$ ' is a measure of breadth of distribution of elements (Jonscher 1978). The low frequency part appears to be the commencement of yet another semicircle inclined with real axis and not fully covered within the frequency range studied. Extrapolation of this plot produces a depressed semicircle as reported earlier (Padmasree et al 2005). Hence, from the point of intersection of the semicircular part on the $Z^{\prime}$-axis, the corresponding value of $R_{\mathrm{b}}$ was determined by employing the internally incorporated software package with an excellent accuracy, for all the nine different specimens. Subsequently, room temperature electrical conductivity $\left(\sigma_{298} \mathrm{~K}\right)$ values were estimated from the general relationship

$$
\sigma=t /\left(A^{*} R_{\mathrm{b}}\right),
$$

where $t$ denotes the thickness of the sample pellet and $A$ its area of cross-section. It is also obvious from figure 4 that the point of intersection on the real axis is shifted towards origin and the diameter of the semicircular arc decreases with increase in temperature and hence the value of bulk resistance $\left(R_{\mathrm{b}}\right)$ decreases at elevated temperatures which in turn leads to an increase in the electrical conductivity value with increase in temperature (Suthanthiraraj and Premchand 2004).

The experimentally determined $\sigma_{298} \mathrm{~K}$ values for nine different compositions of the mixed system having $x=0.9$, $0.8,0.7,0.6,0.5,0.4,0.3,0.2$ and 0.1 mole fraction were found to be $3.8 \times 10^{-6}, 2.7 \times 10^{-4}, 1.1 \times 10^{-4}, 4.3 \times 10^{-4}$, $3.5 \times 10^{-4}, 4.1 \times 10^{-4}, 3.2 \times 10^{-2}, 4.7 \times 10^{-4}$ and $3.9 \times 10^{-6}$ $\mathrm{S} \mathrm{cm}^{-1}$, respectively. It is seen from these conductivity $(\sigma)$ data that the feasibility of realization of typical $\sigma$ values of the order of $10^{-4} \mathrm{~S} \mathrm{~cm}^{-1}$ in the case of samples containing $x=0.8,0 \cdot 7,0.6,0.5,0.4$ and 0.2 mole fraction may be attributed to the presence of $\mathrm{AgI}$ in such compositions (Chandra 1981). The fact that the formation of AgI as one of the constituents in these compositions has already been revealed from XRD and DSC results tend to reconfirm the mechanism of possible ion exchange reactions occurring between $\mathrm{SbI}_{3}$ and $\mathrm{Ag}_{2} \mathrm{CrO}_{4}$. Interestingly, the composition containing 0.3 mole fraction of $\mathrm{SbI}_{3}$ corresponding to $x=$ 0.3 mole fraction was found to be the best conducting composition owing to its highest room temperature conductivity of $3.2 \times 10^{-2} \mathrm{~S} \mathrm{~cm}^{-1}$.

Hence, at the above room temperature, electrical conductivity data appear to indicate that there is a systematic trend in the variation of conductivity of the chosen system probably due to the formation of AgI in the synthesized samples as revealed by the present XRD and DSC results. It is, therefore, expected that similar behaviour would be exhibited by different compositions in their iontransport properties too as reported in a number of similar mixed systems including $x \mathrm{CuI}-(100-x)\left[2 \mathrm{Ag}_{2} \mathrm{O}-0 \cdot 7 \mathrm{~V}_{2} \mathrm{O}_{5}-\right.$ $\left.0 \cdot 3 \mathrm{~B}_{2} \mathrm{O}_{3}\right]$ (Murugesan et al 2008), $x \mathrm{CdI}_{2}-(100-x)\left[2 \mathrm{Ag}_{2} \mathrm{O}-\right.$ $\left.\left(0 \cdot 7 \mathrm{~V}_{2} \mathrm{O}_{5}-0 \cdot 3 \mathrm{~B}_{2} \mathrm{O}_{3}\right)\right]$ (Padmasree et al 2005), $\mathrm{CuI}-\mathrm{Ag}_{2} \mathrm{O}-$ $\mathrm{V}_{2} \mathrm{O}_{5}$ (Chandrasekar and Suthanthiraraj 1993), $\mathrm{CdI}_{2}-\mathrm{Ag}_{2} \mathrm{O}-$ $\mathrm{MoO}_{3}$ (Suthanthiraraj and Ganeshkumar 2001), $\mathrm{PbI}_{2}-$ $\mathrm{Ag}_{2} \mathrm{O}-\mathrm{V}_{2} \mathrm{O}_{5}, \mathrm{PbI}_{2}-\mathrm{Ag}_{2} \mathrm{O}-\mathrm{TeO}_{2}$ and $\mathrm{PbI}_{2}-\mathrm{Ag}_{2} \mathrm{O}-\mathrm{P}_{2} \mathrm{O}_{5}$ (El Damrawi et al 2000) etc. According to El Damrawi et al (2000), in the case of $\mathrm{PbI}_{2}-\mathrm{Ag}_{2} \mathrm{O}-\mathrm{TeO}_{2}$ and $\mathrm{PbI}_{2}-\mathrm{Ag}_{2} \mathrm{O}-$ $\mathrm{P}_{2} \mathrm{O}_{5}$ networks, the concentration of iodine ions originating from $\mathrm{PbI}_{2}$ is higher than that originating from similar networks such as $\mathrm{AgI}-\mathrm{Ag}_{2} \mathrm{O}-\mathrm{TeO}_{2}$ and $\mathrm{AgI}-\mathrm{Ag}_{2} \mathrm{O}-$ $\mathrm{P}_{2} \mathrm{O}_{5}$. Two iodine ions are provided to the tellurite network upon adding one mole $\mathrm{PbI}_{2}$, whereas only one iodine ion could be accommodated when $\mathrm{AgI}$ is introduced in the same network. Similarly, in the case of the present system also, three iodine ions are likely to be added to the silver chromate network upon adding one mole of $\mathrm{SbI}_{3}$, whereas only one iodine ion could be added in the case of $\mathrm{AgI}-\mathrm{Ag}_{2} \mathrm{CrO}_{4}$ network (Durga Rani and Hariharan Durga 1996).

In the case of the new system, viz. $\left(\mathrm{SbI}_{3}\right)_{x}-\left(\mathrm{Ag}_{2} \mathrm{CrO}_{4}\right)_{1-x}$ $(0.1 \leq x \leq 0.9))$ developed by us, it was also intended to optimize the best conducting composition. Obviously, the addition of $\mathrm{SbI}_{3}$ into the $\mathrm{Ag}_{2} \mathrm{CrO}_{4}$ network in terms of varying concentrations does play an important role in determining the conduction mechanism. As the concentration of $x$ (i.e. 
mole fraction of $\mathrm{SbI}_{3}$ ) increases, the conductivity increases, reaches a maximum value of $3.2 \times 10^{-2} \mathrm{~S} \mathrm{~cm}^{-1}$ for $x=0.3$ mole fraction and then starts decreasing on further addition of $\mathrm{SbI}_{3}$. As observed from the XRD results, typical composition having $x=0.3$ mole fraction, was identified to exhibit a disordered nature, whereas crystalline $\mathrm{AgI}$ phase is found to exist as reaction product between $\mathrm{SbI}_{3}$ and $\mathrm{Ag}_{2} \mathrm{CrO}_{4}$ and was present in compositions corresponding to $x=0 \cdot 1,0 \cdot 2$, $0.4,05$ and 0.6 mole fraction unlike those remaining compositions containing $x=0.7,0.8$ and 0.9 mole fraction possessing relatively higher concentrations of $\mathrm{SbI}_{3}$.

Figure 5 depicts plots of $\log \sigma T$ vs $1 / T$ obtained for nine different compositions of the mixed system $\left(\mathrm{SbI}_{3}\right)_{x}-$ $\left(\mathrm{Ag}_{2} \mathrm{CrO}_{4}\right)_{1-x}$ containing $x=0.9,0.8,0.7,0.6,0.5,0.4$, $0.3,0.2$ and 0.1 mole fraction, respectively over the temperature $(T)$ range $298-435 \mathrm{~K}$. Figure 5 appears to suggest the Arrhenius-type of behaviour of temperature-dependent electrical conductivity in view of the fact that the observed $\sigma$ value is found to increase with increasing temperature in conformity with that of ionic materials (Chandra 1981). In general, the temperature dependence of conductivity $(\sigma)$ in the case of fast ionic solid may be expressed by the Arrhenius relation (Kawamura and Shimoji 1986)

$$
\sigma_{(T)}=\left(\sigma_{0} / T\right) \exp \left(-E_{\mathrm{a}} / k T\right),
$$

where $\sigma_{0}$ is the pre-exponential factor, $E_{\mathrm{a}}$, the activation energy for ionic migration within the solid, $k$, the Boltzmann constant and $T$ the absolute temperature. Accordingly, best fit patterns of all the observed Arrhenius plots shown in figure 5 were drawn with accuracy for the evaluation of relevant activation energy $\left(E_{\mathrm{a}}\right)$ data corresponding to individual compositions. As a consequence, the estimated values of activation energies for the set of nine different compositions containing $x=0 \cdot 9,0 \cdot 8,0 \cdot 7,0 \cdot 6,0 \cdot 5,0 \cdot 4,0 \cdot 3,0 \cdot 2$ and 0.1 mole fractions of $\mathrm{SbI}_{3}$ in the temperature range of $298-403 \mathrm{~K}$ were found to be $0.51,0.4,0.45,0.41,0.3,0.28,0.16,0.26$ and $0.46 \mathrm{eV}$, respectively. From these results, it is clear that highly conducting specimen viz. those corresponding to $x=0.3$ mole

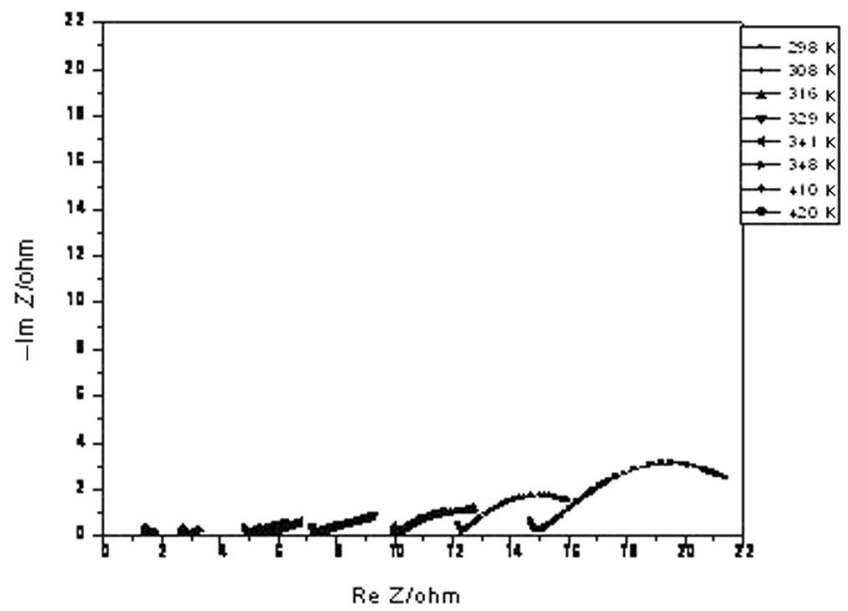

Figure 4. Complex impedance plots obtained for typical composition of mixed system $\left(\mathrm{SbI}_{3}\right)_{0 \cdot 3}-\left(\mathrm{Ag}_{2} \mathrm{CrO}_{4}\right)_{0 \cdot 7}$. fraction, possesses very low activation energies for conduction in good agreement with the observed trend of conductivity among various compositions of the mixed system, $\mathrm{SbI}_{3}-$ $\mathrm{Ag}_{2} \mathrm{CrO}_{4}$. It is quite interesting to note from figure 5 that in the case of compositions corresponding to $x=0.3$ mole fraction and almost in all compositions, there is an abrupt change in the value of conductivity at around $420 \mathrm{~K}$ which may be attributed to the presence of $\mathrm{AgI}$ as a constituent phase in these samples in conformity with the present DSC data.

Table 1 presents summary of electrical transport data obtained for the mixed system, $\left(\mathrm{SbI}_{3}\right)_{x}-\left(\mathrm{Ag}_{2} \mathrm{CrO}_{4}\right)_{1-x}$ (where $x=0.9,0 \cdot 8,0 \cdot 7,0 \cdot 6,0.5,0.4,0 \cdot 3,0.2$ and 0.1 mole fractions, respectively), in terms of the measured values of room temperature electrical conductivity $\left(\sigma_{298} K\right)$ along with silver ionic transport number $\left(t_{\mathrm{Ag}}{ }^{+}\right)$values. It is apparent from table 1 that silver ionic transport number $\left(t_{\mathrm{Ag}}{ }^{+}\right)$data obtained for the system, $\left(\mathrm{SbI}_{3}\right)_{x}-\left(\mathrm{Ag}_{2} \mathrm{CrO}_{4}\right)_{1-x}$ from EMF technique at room temperature include $0.92,0.93,0.93$, $0.94,0.94,0.95,0.99,0.96$ and 0.94 for $x=0.9,0.8,0.7$, $0 \cdot 6,0 \cdot 5,0 \cdot 4,0 \cdot 3,0 \cdot 2$ and $0 \cdot 1$ mole fraction, respectively. It is evident from table 1 that silver ionic transport number $\left(t_{\mathrm{Ag}}{ }^{+}\right)$ data obtained for various compositions lie in the range of $0.92-0.99$, thus indicating the occurrence of silver ionic conduction in the mixed system, $\mathrm{SbI}_{3}-\mathrm{Ag}_{2} \mathrm{CrO}_{4}$ and that for the highly conducting composition having $x=0 \cdot 3$ mole fraction, it is almost unity (i.e. 0.99). These features clearly show that major contribution to the total electrical conductivity in the chosen system may be due to silver ions only as in the case of similar systems such as $\mathrm{AgI}-\mathrm{Ag}_{2} \mathrm{CrO}_{4}$ (Durga Rani and Hariharan 1996), $\mathrm{CuI}-\mathrm{Ag}_{2} \mathrm{MoO}_{4}$ (Viswanathan and Suthanthiraraj 1992), $\mathrm{PbI}_{2}-\mathrm{Ag}_{2} \mathrm{O}-\mathrm{WO}_{3}$ (Suthanthiraraj and Vinod Mathew 2005), $\mathrm{Cu}_{1-x} \mathrm{Ag}_{x} I-\mathrm{Ag}_{2} \mathrm{O}-\mathrm{B}_{2} \mathrm{O}_{3}$ (Suthanthiraraj et al 2001), CuI- $\mathrm{Ag}_{3} \mathrm{AsO}_{4}$ (Rivolta et al 1988), $\mathrm{CuI}-\mathrm{Ag}_{2} \mathrm{WO}_{4}$ and $\mathrm{CuI}-\mathrm{Ag}_{2} \mathrm{CrO}_{4}$ (Suthanthiraraj and Premchand 2004). It is evident from the present XRD and DSC data that AgI exist as one of the constituent phases in the case of compositions having $x=0 \cdot 1,0.2$ and 0.3 mole fractions. Pure AgI was reported to possess an electronic transference number at around $0.08 \pm 0.02$ at $293 \mathrm{~K}$ (Hoshino and Shimoji 1974), thus suggesting an ionic transference number of 0.92 \pm 0.02 at ambient conditions. During the present investigation, the observed silver ionic transport number data for various compositions lie in the region of 0.92-0.99. The fact that the best conducting composition having $x=0.3$ exhibits the highest silver ionic transport number $\left(t_{\mathrm{Ag}+}\right)$ of 0.99 implying that in addition to AgI, the presence of a probable silver ion-based disordered phase may also give rise to the appreciably high silver ionic transport number in this particular specimen. In other words, $\mathrm{Ag}^{+}$ ions are found to be effective mobile species in most of the compositions synthesized during the present work.

\subsection{Conductivity spectra}

Figure 6 depicts conductivity spectra (i.e. $\log \sigma$ vs $\log$ $\omega$ plots) observed for the best conducting composition, 
Table 1. Summary of electrical transport data obtained for the system, $\left(\mathrm{SbI}_{3}\right)_{x}-\left(\mathrm{Ag}_{2} \mathrm{CrO}_{4}\right)_{1-x}$.

\begin{tabular}{|c|c|c|c|c|}
\hline \multirow{2}{*}{$\begin{array}{l}\text { Composition, } x \\
\text { (Mole fraction) }\end{array}$} & \multirow{2}{*}{$\begin{array}{c}\text { Room } \\
\text { temperature } \\
\text { conductivity, } \\
\sigma_{298 \mathrm{~K}}\left(\mathrm{~S} \mathrm{~cm}^{-1}\right)\end{array}$} & \multicolumn{2}{|c|}{$\begin{array}{l}\text { Silver ionic transport number data } \\
\text { (EMF method) }\end{array}$} & \multirow{2}{*}{$\begin{array}{c}\text { Activation energy, } \\
E_{\mathrm{a}}(\mathrm{eV})\end{array}$} \\
\hline & & $\overline{\mathrm{OCV}}\left(E_{\mathrm{t}}\right)(\mathrm{mV})$ & $t_{\mathrm{Ag}}{ }^{+}$ & \\
\hline 0.9 & $3 \cdot 8 \times 10^{-6}$ & $632 \cdot 0$ & 0.92 & 0.51 \\
\hline 0.8 & $2.7 \times 10^{-4}$ & 638.9 & 0.93 & 0.40 \\
\hline 0.7 & $1.1 \times 10^{-4}$ & 638.9 & 0.93 & 0.45 \\
\hline 0.6 & $4.3 \times 10^{-4}$ & $645 \cdot 7$ & 0.94 & 0.41 \\
\hline 0.5 & $3.5 \times 10^{-4}$ & $645 \cdot 7$ & 0.94 & $0 \cdot 30$ \\
\hline $0 \cdot 4$ & $4.1 \times 10^{-4}$ & $652 \cdot 6$ & 0.95 & 0.28 \\
\hline $0 \cdot 3 *$ & $3 \cdot 2 \times 10^{-2}$ & $680 \cdot 1$ & 0.99 & $0 \cdot 16$ \\
\hline $0 \cdot 2$ & $4.7 \times 10^{-4}$ & $659 \cdot 5$ & $0 \cdot 96$ & $0 \cdot 26$ \\
\hline $0 \cdot 1$ & $3.9 \times 10^{-6}$ & $645 \cdot 7$ & 0.94 & 0.46 \\
\hline
\end{tabular}

*Best conducting composition.

$\left(\mathrm{SbI}_{3}\right)_{0 \cdot 3}-\left(\mathrm{Ag}_{2} \mathrm{CrO}_{4}\right)_{0.7}$, at four different temperatures in the range of 298-388 K. The observed conductivity spectra comprised of three regions viz. low-frequency region, a frequency-independent plateau region corresponding to d.c. conductivity in addition to the high frequency dispersion region, indicating to obey Jonscher's universal power law (Baskaran et al 1997) as in the case of other fast ionic conductors

$$
\sigma(\omega)=\sigma(0)+A \omega^{n} .
$$

The values of the fitting parameters $A, n$ and $\sigma(0)$ estimated at four different temperatures viz. 298, 316, 348 and $388 \mathrm{~K}$ are presented in table 2 . Knowing the values of $n, A$ and $\sigma(0)$, the values of hopping rate of the mobile species, $\omega_{\mathrm{p}}$, were calculated (Radhakrishnan and Chowdari 1987) using the relation

$$
\omega_{\mathrm{p}}=[\sigma(0) / A]^{1 / n},
$$

i.e. at a point where $\sigma(\omega)=2 \sigma(0)$ and $\omega_{\mathrm{p}}$ has been identified as the hopping rate of $\mathrm{Ag}^{+}$ions. It may be seen from table 2 that $\omega_{\mathrm{p}}$ shifts to higher frequencies as the temperature is increased from 298 to $388 \mathrm{~K}$. The fitting parameters $A, n$ and $\sigma(0)$ have been found to be strongly temperaturedependent i.e. ' $A$ ' values increase with increase of temperature while ' $n$ ' values decrease with increasing temperature, whereas $\sigma(0)$ values estimated from the conductivity spectral analysis are in good agreement with those calculated from impedance plots as in the case of other silver ion conducting solid electrolytes.

\section{Conduction mechanism}

It is clear that $\left(\mathrm{SbI}_{3}\right)_{x}-\left(\mathrm{Ag}_{2} \mathrm{CrO}_{4}\right)_{1-x}$, material acts as a fast ionic conductor with properties similar to that of silver ion

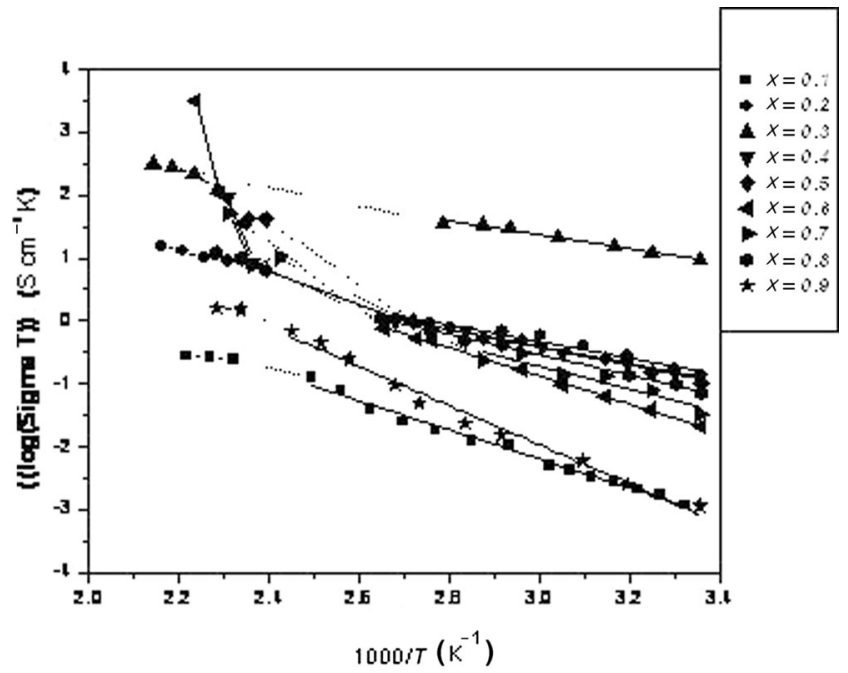

Figure 5. Arrhenius plots of electrical conductivity obtained for composition of mixed system $\left(\mathrm{SbI}_{3}\right)_{x}-\left(\mathrm{Ag}_{2} \mathrm{CrO}_{4}\right)_{1-x}(0 \cdot 1 \leq x \leq$ $0 \cdot 9)$.

conducting solid electrolytes reported in the mixed system, $\mathrm{AgI}-\mathrm{Ag}_{2} \mathrm{CrO}_{4}$ (Durga Rani and Hariharan 1996). It is well known that fast ionic transport is favoured by any sublattice comprising a large and highly polarizable anion, e.g., $\mathrm{I}^{-}$, in combination with a relatively small and polarizable metal ion, e.g., $\mathrm{Ag}^{+}$(Baskaran 2002). The formation of highly conducting composition in the present system may be explained on the basis of hard and soft acids and bases (HSAB) principle proposed by Pearson (1963). The HSAB rule states that soft acids prefer to bind to soft or polarizable bases and those hard acids would prefer to bind to hard or non-polarizable bases as a result of various degrees of ionic and covalent bonding. It is therefore possible that silver iodide is formed during the ion exchange reaction between antimony iodide and the silver oxy-salt, $\mathrm{Ag}_{2} \mathrm{CrO}_{4}$ as in an acid-base reaction

$$
\mathrm{A}:+: \mathrm{B} \rightarrow \mathrm{A}: \mathrm{B}
$$


Table 2. Values of temperature-dependent electrical conductivity parameters for the sample, $\left(\mathrm{SbI}_{3}\right)_{0 \cdot 3}-\left(\mathrm{Ag}_{2} \mathrm{CrO}_{4}\right)_{0 \cdot 7}$.

\begin{tabular}{|c|c|c|c|c|}
\hline Temperature (K) & $n$ & $A\left(\mathrm{~S} \mathrm{~cm}^{-1} \mathrm{rad}^{-n}\right)$ & $\sigma(0)\left(\mathrm{S} \mathrm{cm}^{-1}\right)$ & Hopping rate, $\omega_{\mathrm{p}}=[\sigma(0) / A]^{1 / n}\left(\mathrm{rad} \mathrm{s}^{-1}\right)$ \\
\hline 298 & 0.49 & $8 \times 10^{-7}$ & $3 \cdot 2 \times 10^{-2}$ & $2 \cdot 1 \times 10^{9}$ \\
\hline 316 & $0 \cdot 4$ & $5 \times 10^{-6}$ & $4.7 \times 10^{-2}$ & $1 \times 10^{10}$ \\
\hline 348 & $0 \cdot 39$ & $5.4 \times 10^{-6}$ & $9.8 \times 10^{-2}$ & $2 \cdot 8 \times 10^{10}$ \\
\hline 388 & $0 \cdot 24$ & $4 \times 10^{-5}$ & $9.9 \times 10^{-2}$ & $7.9 \times 10^{13}$ \\
\hline
\end{tabular}

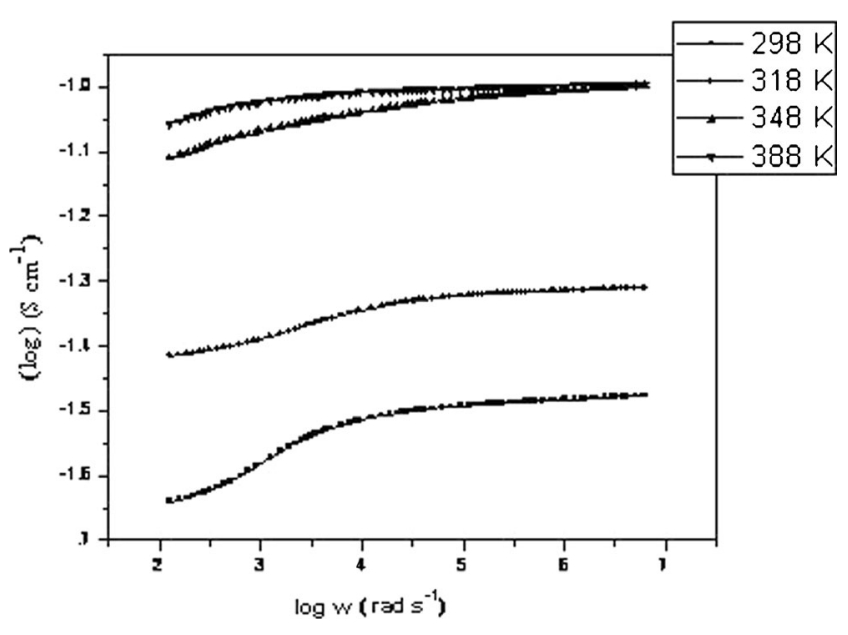

Figure 6. Conductivity spectra for composition $\left(\mathrm{SbI}_{3}\right)_{0.3}-$ $\left(\mathrm{Ag}_{2} \mathrm{CrO}_{4}\right)_{0 \cdot 7}$.

where the reaction product $\mathrm{A}: \mathrm{B}$ is known as coordination compound or an acid-base complex (Viswanathan and Suthanthiraraj 1992). According to the HSAB concept, hard acids prefer binding to the hard bases to give ionic complexes, whereas the soft acids prefer binding to soft bases to give covalent complexes. The large electronegativity differences between hard acids and hard bases give rise to strong ionic interactions. Their small sizes allow the acid and base to get close enough together so that the ionic interaction is quite strong. The electronegativities of soft acids and soft bases are almost similar and hence have less ionic interactions. i.e. interactions between them are more covalent because their electron clouds are polarizable. Thus, a strong interaction occurs between large metal ions with high electronegativity and the most polarizable bases. Since $\mathrm{SbI}_{3}$ is an intermediate acid, the soft acid $\mathrm{Ag}^{+}$and soft base $\mathrm{I}^{-}$prefer to form AgI clusters in agreement with the above principle whenever the concentration (in terms of $\mathrm{mol} \%$ ) of $\mathrm{SbI}_{3}$ present in the mixture during the melting process is sufficient. During the melting process, initially $\mathrm{Ag}_{2} \mathrm{O}$ may decompose into metallic silver and oxygen. Metallic silver released from $\mathrm{Ag}_{2} \mathrm{O}$ could possibly be involved in the exchange reaction with $\mathrm{SbI}_{3}$, thus forming AgI. Similar ion exchange reactions have been reported by earlier researchers as well (Padmasree and Kanchan 2006; Suthanthiraraj and Sankaran 2012; Suthanthiraraj and Sarumathi 2012).
Usually, the acid-base combination would result in the formation of a complex ion or in an electrically neutral compound. Silver iodide may be assumed to be a Lewis acid-base combination. Hence, $\mathrm{AgI}$ will be formed while $\mathrm{SbI}_{3}$ is melted together with $\mathrm{Ag}_{2} \mathrm{CrO}_{4}$ in accordance with the HSAB principle. The fact that $\mathrm{CrO}_{3}$ glass former is a strong oxidant and that $\mathrm{Cr}^{6+}$ entity in $\mathrm{Ag}_{2} \mathrm{CrO}_{4}$ is also strongly oxidizing may favourably influence the incorporation of $\mathrm{SbI}_{3}$ in building up an appropriate structural network wherein the presence of larger $\mathrm{I}^{-}$ions would give rise to an ion exchange reaction occurring between $\mathrm{I}^{-}, \mathrm{Sb}^{3+}$ and $\mathrm{Ag}^{+}$ions as in the case of Lewis acid-base type of reactions. Owing to such a specific exchange mechanism, there is a feasibility of an apparent substitution of $\mathrm{Ag}$ bonded to non-bridging oxygen (NBO) sites by $\mathrm{Sb}$ in order to form $\mathrm{AgI}$ phase, thus releasing $\mathrm{Ag}^{+}$ions which would become available for an enhanced ionic conductivity of the present fast ion conducting system. Addition of metal oxide to a glass former usually involves incorporation of oxygen into the macromolecular chain formed by the network former, thereby introducing ionic bonds into the glass. Such incorporation depends mainly on the coordination chemistry of the glass former element. When the ratio of glass modifier to glass former content increases, a larger number of oxygen bridges are likely to be broken and as a consequence of the enhanced number of nonbridging oxygen atoms (NBOs), the average length of the macromolecular chain decreases. In fact, an increase in the content of $\mathrm{Ag}_{2} \mathrm{O}$ was reported to give rise to breakage of bonds, thereby facilitating an easy migration of the conducting species viz. $\mathrm{Ag}^{+}$ ions (Sarma and Radhakrishna 1991).

\section{Conclusions}

The physic-chemical characterization of $\left(\mathrm{SbI}_{3}\right)_{x}-$ $\left(\mathrm{Ag}_{2} \mathrm{CrO}_{4}\right)_{1-x}$ mixed system has indicated that a typical composition viz. $\left(\mathrm{SbI}_{3}\right)_{0.3}-\left(\mathrm{Ag}_{2} \mathrm{CrO}_{4}\right)_{0.7}$ would exhibit an appreciably high silver ion conductivity of $3.2 \times 10^{-2} \mathrm{~S}$ $\mathrm{cm}^{-1}$ at $298 \mathrm{~K}$ with an activation energy value of $0.16 \mathrm{eV}$. $\mathrm{XRD}$ and DSC analyses have confirmed the occurrence of an exchange reaction between $\mathrm{SbI}_{3}$ and $\mathrm{Ag}_{2} \mathrm{CrO}_{4}$, which could be accounted for the observed fast ionic transport owing to the formation of AgI within the disordered network as revealed by thermal analysis. 


\section{References}

Archer W I and Armstrong R D 1980 Electrochim. Acta 251689

Armstrong R D, Dickinson T and Willis P M 1974 Electroanal Chem. Interf. Electrochem. $\mathbf{5 3} 389$

Armstrong R D, Dickinson T and Whitfield R 1972 J. Electroanal. Chem. 39257

Baskaran N, Govindaraj G and Narayanasamy A 1997 Solid State Ionics 98217

Baskaran N 2002 J. Appl. Phys. 92825

Bhattacharya S and Ghosh A 2005 Solid State Ionics 1761243

Biendicho J J, West A R 2012 Solid State Ionics 22641

Boukamp B A 1986 Solid State Ionics 18-19 136

Boukamp B A 2000 Solid State Ionics 136-137 75

Boukamp B A 2004 Solid State Ionics 16965

Chandra S 1981 Superionic solids-Principles and applications (New York: North Holland Publishing Company) p. 17

Chandrasekar V G and Suthanthiraraj S A 1993 J. Mat. Sci. 284043

Dalvi A, Awasthi A M, Bharadwaj S and Shahi K 2005 Phys. Chem. Solids 66783

Durga Rani A N and Hariharan K 1996 Mater. Chem. Phys. 43 243

El Damrawi G, Hassan A K and Doweidar H 2000 Physica B 291 34

Hodge I M, Ingram M D and West A R 1976 J. Electroanal. Chem. 74125

Hoshino H and Shimoji M 1974 J. Phys. Chem. Solids 35321

Hull S, Keen D A, Sivia D S and Berastegui P 2002 J. Solid State Chem. 165363

JCDPS File No-740456

JCDPS File No-780641

JCDPS File No-720858

JCPDS File No-351288

Jonscher A K 1978 J. Mat. Sci. 13553

Kanchan D K, Padmasree K P and Panchal H R 2004 Ceram. Intern. 301655

Kawamura J and Shimoji M 1986 J. Non-Cryst Solids 88281

Macdonald J R 1973 J. Chem. Phys. 584982

Macdonald J R 1974 J. Chem. Phys. 613977

Macdonald J R 1987 Impedance spectroscopy. Wiley-Interscience, New York, p. 206

Macdonald J R 1992 Ann. Biomed. Eng. 20289

Minami T 1983 J. Non-Cryst Solids 5615
Metikos M, Hukovic and Grubac Z 2003 J. Electroanal.Chem. 556 167

Murugesan S, Wijayasinghe A and Bergman B 2008 J. Non-Cryst. Solids 3541066

Nowinski J L, Ksiezopolski M K, Garbarczyk J E and Wasiucionek M 2007 J. Power Sources 173811

Padmasree K P, Kanchan D K, Panchala H R, Awasthi A M and Bharadwaj S 2005 Solid State Commun. 136102

Padmasree K P and Kanchan D K 2006 J. Non-Cryst. Solids 352 3841

Patnaik J R G and Sunandana C S 1998 J. Phys. Chem. Solids 59 1059

Pearson R G 1963 J. Am. Chem. Soc. 853533

Pyung-An Ahn, Eui-Chol Shin, Gye-Rok Kim and Jong-Sook L 2011 J. Korean Ceram. Soc. 48549

Radhakrishnan K and Chowdari B V R 1987 Solid State Ionics 24 225

Renard C, Coquet G and Bychkov E 2002 Solid State Ionics 154155749

Rivolta B, Bonino F and Scrosati B 1988 Mater. Chem. Phys. 19 557

Sarma R V G K and Radhakrishna S 1991 J. Solid State Chem. 91 204

Saito T, Tatshumisago M and Minami T 1993 Solid State Ionics 61 285

Suthanthiraraj S A and Daniel Premchand Y 2004 J. Solid State Chem. 1774126

Suthanthiraraj S A and Ganeshkumar A C 2001 Indian J. Eng. \& Mater. Sci. 8352

Suthanthiraraj S A and Mala R 2003 J. Solid State Electrochem. 7 232

Suthanthiraraj S A, Murugesan S and Maruthamuthu P 2001 Solid State Ionics 143413

Suthanthiraraj S A and Vinod Mathew 2005 Indian J. Phys. 79753

Suthanthiraraj S A and Sankaran V S 2012 Ionics doi:10.1007/ s11581-012-0804-y

Suthanthiraraj S A and Sarumathi R 2012 Ionics doi:10.1007/ s11581-012-0826-y

Veeranna Gowda V C and Anavekar R V 2007 J. Mat. Sci. 423816

Viswanathan A and Suthanthiraraj S A 1992 Solid State Ionics 58 89

Viswanathan A and Suthanthiraraj S A 1993 Mater. Res. Bull. 28 821 